\title{
RESISTENCIAS FEMINISTAS EN CHILE: SUBJETIVACIONES Y ACCIONES ESTÉTICO-POLIITICAS ANTE LAS VIOLENCIAS NEOLIBERALES
}

\section{Maria Laura Gutiérrez ${ }^{1}$ \\ Camila Arbuet Osuna²}

Resumo: Neste artigo, investigamos as rupturas que os movimentos feministas e LGBTQI+ chilenos criaram para a ação política e política estético-política no âmbito das reações sociais à violência estatal do neoliberalismo. Por meio de uma análise de manifestos, declarações, ações e performances realizadas em 2019, analisamos, por um lado, como esses grupos ressignificaram, no calor da rebelião de outubro, a ligação entre violência e resistência contra os postos avançados conservadores do Chile. E, por outro lado, como procuraram interromper os processos de subjetivação produtivista, sexista, racista e heteronorme típica do negacionismo pinochetista.

Palavras-chave: Feminismos; Chile 2019; resistências.

Abstract: We investigate the disruptions that feminist and LGBTQI+ Chilean movements have created for political and aesthetic-political action in the context of the social reactions to the state violence of neoliberalism. By reviewing manifests, statements, actions and performances carried out in 2019, we analyze the ways in which these groups managed to resignify the relationship between violence and resistance against the advance of the conservative backlash amidst the heat of the October rebellion in Chile. We also provide an account of the ways in which they attempted to disrupt the processes of productivist, sexist, racist, and heteronomous forms of subjectivation that are typical of Pinochetist negationism.

Keywords: Feminism; Chile 2019; resistance.

\footnotetext{
1 Doctora en Ciencias Sociales por la Universidad Nacional de Buenos Aires, Argentina. Docente de la carrera en Ciencia Política de la UNMdP, Argentina. Becaria Posdoctoral CONICET, Argentina. E-mail: mlgutierrezpica@gmail.com. Orcid: 0000-0002-1197-5204

2 Doctora en Ciencas Sociales y Humanas de la Universidad de Quilmes, Argentina. Docente de la Universidad Autónoma de Entre Ríos y de la Universidad Nacional de Entre Ríos, Argentina. E-mail: camila_arbuet@hotmail.com. Orcid: 0000-0001-6834-6487
} 


\section{¡No son 30 pesos, son 30 años! Neoliberalismo y lenguajes de la violencia}

Tiemblen los que tengan que temblar, pues devenimos manada, cascada, erosión, tejido: TRAMA. Una vez que se muestra la ruina tal cual es, con toda su violencia, con toda su atrocidad; pues justo alli se revela la vida que siempre habitó el desierto.

Vitrina Dystópica, No tengo fuerzas para rendirme: saberes desde la revuelta en shile

Uno de los aportes fundamentales de las teorías políticas feministas y queer/cuir ha sido ingresar el estudio de las prácticas de afección como parte de una preocupación insistente por las matrices anestésicas del capitalismo actual. Nos interesa analizar, en el estallido político chileno del 2019, cómo se han encarnado los debates sobre qué subjetivaciones tenemos (y cuáles podemos re-construir) para la acción política en el marco de la necesidad de reacciones sociales al neoliberalismo salvaje. Para ello, trabajamos sobre el gran caudal de textos y acciones producidas por los movimientos feministas, LGBTI+ y cuir chilenos a lo largo del 2019 en el contexto de sus insurgencias populares. En el análisis de dichas formas de organización colectiva y derivas políticas encontramos algunas claves de lectura para comprender cómo se han resignificado, al calor de los acontecimientos, los vínculos posibles entre violencias y resistencia, dando lugar a otros modos de asociarse, subjetivarse y disputar el monopolio de la violencia (i)legítima al Estado conservador.

A inicios de octubre del 2019, en el marco de un nuevo acuerdo con el FMI, el gobierno de Ecuador presidido por Lenin Moreno decide dejar sin subsidio los hidrocarburos produciendo una suba del precio de los combustibles; el estallido social del pueblo ecuatoriano, liderado por organizaciones indígenas, no tarda en escalar obligando a la cúpula gubernamental a trasladar su sede a Guayaquil e imponiendo - a fuerza de resistencia callejera - nuevos términos de negociación. Tan sólo dos semanas después manifestaciones multitudinarias en Chile hacen frente a la decisión de Sebastián Piñera de subir el precio del boleto del metro. A diferencia del escenario ecuatoriano no se divisan líderes ni agrupaciones con las que el gobierno vaya a negociar, la chispa de la suba del boleto sirve de excusa para encolumnar un conjunto de demandas políticas que se vienen sosteniendo activamente desde hace al menos una década, especialmente por parte del movimiento estudiantil: acceso a la educación, la salud pública y la vivienda propia; desendeudamiento y desprecarización laboral; revisión de los 
planes de estudio sexistas, cristianos y moralizantes; suspensión de las políticas y las continuidades institucionales y sociales heredadas de la dictadura ${ }^{3}$; fin del extractivismo, el racismo y la xenofobia; aborto legal; reincorporación de los fondos de pensión privatizados; entre otras. Si bien el aumento del boleto se derogó - tras la evasión masiva de los molinetes y la quema y destrozo en una sola noche de diecinueve estaciones de metro en la capital -, la movilización social no hizo más que crecer mientras las marchas y las concentraciones eran fuertemente reprimidas.

El 20 de octubre (dos días después de haber decretado el estado de sitio), mediante un discurso castrense, el presidente chileno señaló al oponente: "Estamos en guerra contra un enemigo poderoso, implacable, que no respeta a nada ni a nadie y que está dispuesto a usar la violencia y la delincuencia sin ningún límite, que está dispuesto a quemar nuestros hospitales, el metro, los supermercados, con el único propósito de producir el mayor daño posible".

La analogía con la guerra fue contestada de inmediato por la población movilizada que, en primer lugar, decretó rápidamente una huelga general para los días 23 y 24 de octubre pidiendo la derogación del estado de emergencia. Pocos días después del comunicado más de un millón de personas marchaban desplegando una inmensa bandera en la que se leía "Chile despertó. No estamos en guerra". Era el inicio de una batalla sin tregua en las calles que, entre otras tantas cosas, discutiría la noción misma de violencia, disputando la soberanía con el Estado. Si, tal como lo señaló tempranamente Carl Schmitt, la prerrogativa de decidir e imponer quién es amigo y quién es enemigo, asi como de hacer la guerra y la paz, vuelve a la soberana estatidad en los estados de excepción, lo que pone en litigio el escenario chileno es quién es el soberano, discutiendo quién puede decretar la guerra y quién puede afirmar qué es violencia y que no. $Y$ asi como el toque de queda no es respetado mediante sentadas nocturnas, marchas, cacerolazos y proyecciones en edificios, tampoco lo es la imposición del lenguaje bélico para definir la situación. Esto no quiere decir, sin embargo, que la insurgencia chilena haga gala exactamente del pacifismo.

\footnotetext{
3 Tal y como señalamos en el resumen, dichas continuidades pueden ser sostenidas en buena medida por el fogoneado "negacionismo pinochetista", que niega, minimiza o falsea los crímenes y abusos de lesa humanidad cometidos en la última dictadura cívico-militar (1973-1990). La salida "pactada" de la misma, logró, además de evitar que el juicio y castigo a los responsables supusiera la cárcel común para los genocidas, que los militares co-gobernaran con las autoridades democráticamente electas. Pinochet fue el comandante en Jefe de las Fuerzas Armadas hasta 1998 y luego fue nombrado senador vitalicio. Esta característica del proceso chileno supuso la perpetuación de discursos reaccionarios en los medios de comunicación, en boca de funcionarixs públicxs y de figuras eclesiásticas y en diferentes ámbitos de la sociedad civil, que mienten los hechos, los números y los informes de las comisiones de Derechos Humanos. En 2018, como intento de freno de este gesto político se sancionó una ley que caratula como delito de "incitación a la violencia" los dichos negacionistas.
} 
La disputa sobre los usos, niveles y "economías de la violencia" (WOLIN, 2001) se entrelaza de manera muy particular con la configuración de las protestas de los movimientos feministas chilenos. Nos interesa dejar planteada la apertura de un debate político sobre qué hacer con la violencia como parte de la praxis política. Si bien hay cierto consenso dentro de los feminismos sobre que el horizonte de deseabilidad estaría signado por lograr vivir en contextos no violentos, detectamos algunas diferencias en los - por decirlo de algún modo "programas de transición".

Por una parte, alli donde la violencia es pensada como un elemento diferencialmente constitutivo de nuestras subjetividades sexualizadas, generizadas, racializadas, etnizadas y configuradas por las clases que distribuye desigualmente el miedo sobre los cuerpos (MEDEAK, 2014); se ha planteado la inminencia de "reapropiarnos de las técnicas performativas de la violencia" (PRECIADO, 2009), para evitar que todas las formas de pensar y de hacer en la política sean cooptadas por la lengua de los derechos y/o del Estado. Esto no supone, obviamente, dejar de reclamar diferentes ejes programáticos - como, por ejemplo, los que elevó el Programa feminista contra la precarización de la vida de la Coordinadora Feminista Chilena (PLAN..., 2020) -, sino correr el foco pasando de pensar la legitimidad de las negociaciones con un gobierno ilegítimo a construir otras formas políticas de agenciar, aparecer, molestar y disputar el monopolio del lenguaje de la violencia y la instigación. Consideramos que la invención de y la provocación callejera se apropiaron de estos modos en sus acciones insurgentes. Diversas performances, acciones, encuentros colectivos en espacios públicos, manifiestos y comunicados dan cuenta de los acuerdos pero también de los disensos en cómo disputar con, contra y a pesar del Estado.

Por otra parte, alertas ante el peligro de no convertirnos en lo que criticamos, podríamos retomar algunos de los análisis que realiza Butler (2020, p. 77) cuando distingue y diferencia violencia de agresión. Recuperando lo dicho en Marcos de guerra (BUTLER, 2010, p. 77), la autora señala en una entrevista reciente que:

Acepto que la agresión forma parte de la vida y, por lo tanto, forma también parte de la política. Pero la agresión puede y debe separarse de la violencia (la violencia es una forma que adopta la agresión), y hay maneras de dar forma a la agresión que obran al servicio de la vida democrática, entre ellas el antagonismo y el conflicto discursivo, las huelgas, la desobediencia civil e, incluso, la revolución. 
En términos simples lo que diferenciaría la agresión de la violencia sería la motivación de dañar que definiría a esta última, siendo una característica propia de las lógicas de las guerras liberales a las que no les basta con "neutralizar" al enemigo. Desde este punto de vista butleriano una política feminista no debiera dudar en señalar que no hay violencia justa, del mismo modo que no hay guerras justas, sólo hay discursos legitimados por el poder (por lo general estatal) que vuelven a ciertas precariedades susceptibles de ser minimizadas, no contadas, no lloradas. Si bien registramos ese uso diferencial de la cuenta de la violencia por parte del Estado chileno ${ }^{4}$, también (disintiendo con Butler) consideramos que - sin caer en un panegírico de la productividad social del odio - la ira, la furia e incluso el odio, propios del hartazgo colectivo que se plantea en la lógica de la movilización permanente y la huelga general chilenas, son formas de la violencia que defienden una idea de justicia, aunque esta no sea ni pretenda ser (a diferencia de la del Estado) siempre igual a si misma, hegemónica y cerrada.

Podríamos decir que, por más que el pueblo chileno no se haya decretado en guerra, la lógica de la guerra azuzada por el Estado se impuso en la estructura política interna y se hizo paulatinamente más difícil encarnar como parte de una "agresión revolucionaria" - a lo Butler - ese deseo colectivo movilizado de "cambiarlo todo" que no negocia con el establishment. Se trata, en cambio, de un tipo de violencia fundacional "mítica" en la categorización clásica de Walter Benjamin) que dice "no" a todos los intentos de pacificación: no a la "Agenda Mujer", no al "Aula Segura", no al "Acuerdo de paz social", no a la reforma constituyente sin representación de los movimientos sociales.

De modo que el paradigma de la guerra se cuela igual, no sólo como forma de resistencia contra la máxima violencia estatal sino también internamente,

\footnotetext{
4 Tal es el caso de la ex-ministra del Ministerio de la Mujer, Isabel Plá, que mientras no tomaba las numerosas denuncias por acoso y violación por parte de las Fuerzas Armadas a civiles durante las virulentas represiones en el estado de sitio - alegando que "hasta ahora no había recibido denuncias de esa naturaleza" -, se condolía por las agresiones a carabineras.

5 La Agenda Mujer es una serie de medidas impulsadas por el gobierno de Piñera en mayo de 2018 que se presentaron como parte del progresismo para equiparar las relaciones jurídicas y laborales entre varones y mujeres, medidas que van desde terminar con legislaciones decimonónicas sobre el patrimonio y el tiempo de espera de la mujer para volver a contraer matrimonio hasta la implementación de dispositivos de denuncia por acoso y discriminación. La Agenda fue fuertemente criticada por insuficiente, tutelar y por ser un artilugio para consensuar con parte del movimiento feminista más estatizado que se basa en un fuerte componente biogenérico del ser mujer.

6 El Aula Segura es una ley aprobada en diciembre de 2018 por el Gobierno de Piñera que, bajo el discurso de la seguridad en los espacios escolares, faculta, entre otras cosas, a los directores de los establecimientos educacionales a expulsar y cancelar la matrícula de manera inmediata de aquellxs estudiantes que estén involucradxs en actos violentos, que causen daños a la institución o generen algún perjuicio a quien forme parte de ella. La resistencia estudiantil a la misma se basa en que la ley habilita una política represiva no sólo al interior de los espacios educativos, con el permiso del ingreso de fuerzas policiales a las aulas, sino también a una cacería de estudiantes organizadxs en protestas y detenidxs por dichas fuerzas.
} 
como una guerra sin cuartel (FEDERICI, 2011; SEGATO, 2017) contra el conjunto de prácticas y discursos sistemáticos y cotidianos que han logrado la perpetuación y recodificación de formas sexistas, castrenses, privadas y católicas de una virulencia y primitividad notorias. Disciplinamiento, control y explotación aparecen como el entramado contra el que se levanta la acción insurgente, un gesto que insta a "no darles el gusto de poder masacrarnos". Así en medio de la cascada de textos escritos al calor de la revuelta, el 10 de noviembre, en el $\checkmark$ Comunicado Intergaláctico se lee (DYSTÓPICA, 2019, p. 29):

\footnotetext{
La guerra deja abierta y expone los artefactos caseros con los que nos cocinamos este bricolaje hechizo que es una vida, esta vida en la calle pese a todo y con todo el aguante, poniendo en común las ollas, las comidas, haciendo estallar la clausura de la imaginación política en lo doméstico, ya que como nos dijeron les cabres: lo personal es político, es decir, violencia y poder, pero también alegre rebeldía. $O$, como nos escribimos en los muros: "le ganamos a la sertralina" ya que "no era depresión, era capitalismo".
}

Es asi como en medio del largo acontecer chileno, que ya a esta altura registra más de 30 asesinatos, 195 querellas por violaciones y violencia sexual, 951 denuncias por tortura y tratos crueles y que ha dejado 3.765 lesionadxs ${ }^{7}$ (entre ellxs 445 con traumas oculares), es posible seguir preguntando sobre la necesidad inminente de vidas que merezcan ser vividas, una urgencia que no negocia con la mera reproductibilidad y subsistencia. Si, como señalaban en las calles chilenas, tras un proceso de desposesión violenta al que ha sido sometida la población en el oasis neoliberal del cono sur, la precarización de la vida ha llegado a extremos tales que ya "no tenemos nada que perder" o "nos deben una vida", el miedo no ha logrado congelar ni la acción ni las preguntas políticas más a mediano y largo plazo. El terrorismo de Estado no ha conseguido ser petrificante y en medio de una represión brutal, que ha trascendido las barreras mediáticas, Ixs manifestantes siguen volviendo críticamente sobre su hacer. Aparecen asi en diversos modos los siguientes interrogantes: ¿cómo pensamos la imaginación política del presente? ¿qué formas teóricas y políticas de afectarnos construimos para desestabilizar las promesas de felicidad, reproductibilidad y sacrificio - entre otras - que convierten nuestra vulnerabilidad en docilidad y aceptación de un futuro diagramado por el capital? ¿qué estrategias

7 Datos aportados por el Instituto Nacional de Derechos Humanos (2019) en su último informe, contando los casos desde octubre de 2019 a febrero de 2020. Que se contradicen bastante con el de la Human Rights Watch que contabiliza 42 muertxs, más de 15 mil las personas detenidas, 11.564 heridos y 442 querellas por torturas y abusos sexuales por parte de Carabineros. 
de acción y cuáles contradicciones nos llegan desde las potentes genealogías de las feministas aguafiestas o lxs queers infelices para disputar tanto las alianzas feministas como los avances neoliberales sobre las poblaciones LGBTI+ y nuestras invenciones de futuro?

\section{Revueltas feministas. Alianzas, acciones y desacatos}

El 8 de marzo de 2019 en Santiago de Chile se llevó adelante la manifestación más grande de la que se tenía registro desde la post dictadura: la huelga general feminista. La misma se tejió al calor del llamado a las huelgas internacionales de mujeres y feministas que se venían desarrollando desde el año 2017. Su resonancia en la interrupción del trazado público será la chispa que quedará latente unos meses más adelante durante la insurgencia de octubre.

Las alianzas entre los distintos colectivos feministas y LGBTI+ en Chile, a pesar de sus diferencias históricas, quedarán articuladas en su gran mayoría en una gran Coordinadora Feminista, desde el 8 de marzo de 2019. La misma pasa a ser parte, a mediados ese año, de Unidad Social - un espacio de referencia de varias organizaciones sociales movilizadas, sindicatos y federaciones de estudiantes - de la que, sin embargo, termina por retirarse en enero del 2020 tras denunciar la cooptación de ese grupo por el Bloque Sindical - dirigido por una burocracia. Bloque que inicia una negociación con Piñera que promete una salida del conflicto a costa de dejar de pedir su renuncia; de no insistir con las huelgas generales y de no sostener la dinámica asamblearia con los movimientos territoriales. Contra esa alianza sindical-patriarcal, la Coordinadora Feminista junto con la Asamblea Feminista Plurinacional, Ni Una Menos Chile, las redes de actrices (Rach), docentes (Redofem), abogadas feministas (Abofem) y la red de mujeres mapuche, insiste en la no negociación con el presidente (i)legítimo.

La fuerza del movimiento feminista chileno y su papel transversal en el sostenido proceso de revuelta popular, que no deja de impresionar por la intensidad de su insistencia, es claramente reconocida como un verdadero peligro por el gobierno de Piñera, que no ha escatimado esfuerzos en intentos de asimilación/cooptación - tras darse cuenta de que no puede simplemente desarmarlo. No es menor señalar que, desde inicio del 2020, cierta agenda liberal de derechos de las mujeres y las disidencias sexuales ha encontrado ecos en el otrora inflexible y conservador congreso chileno que ha puesto en vigencia la ley de identidad de género ${ }^{8}$, ha aprobado en diputados la ley de

8 Ley que estaba congelada desde diciembre de 2018 
paridad de género y una ley para reconocer los derechos laborales de madres lesbianas, y acaba de aprobar "en general" el proyecto de ley del matrimonio igualitario. Si bien es evidente que dichas conquistas en materia de derechos son producto de la fuerte presión de los colectivos feministas y LGBTI+, también lo es el intento conciliarista de un presidente neoliberal de socavar las alianzas entre estos movimientos en nombre de un reconocimiento de derechos y de "inclusión" que poco tienen que ver con su política de precarización de la vida sobre esos mismos colectivos. Las resistencias a los intentos de asimilación se harán oír dentro de los colectivos chilenos activos que, rápidamente, salieron a señalar cómo las nuevas leyes son de plano insuficientes para mejorar su calidad y expectativa de vida en un país donde lesbianas, maricas, travas y trans son masacradxs diariamente.

Estos intentos no son nuevos ni desconocidos en la región pero, en efecto, han tenido en Chile una política larga de tracciones con el Estado ya desde la década de los 90 alrededor de las llamadas "políticas de diversidad". Modulaciones subjetivas y estatales que, siguiendo a Jasbir Puar, podríamos llamar homonacionalistas ${ }^{9}$, que plantean una reconfiguración del orden que pasa de desconocer, perseguir y criminalizar las formas de vida y alianzas de cuidado y familia de estas identidades - históricamente por fuera del Estado-Nación - a clamar por su inclusión. Un ingreso muchas veces instrumentalizado en el presente, a partir del reconocimiento de reclamos específicos entrelazados con políticas discriminatorias de construcción colonial (PUAR, 2007, 2013). Así, la articulación de las identidades lesbianas y gay - fundamental, pero no exclusivamente - promovidas a partir del acceso al consumo del "mercado rosa" neoliberal en lugar de dirigirse al cuestionamiento de las asunciones heteronormativas del Estado-Nación, supondrían una reproducción de la heteronormatividad capitalista, donde se accedería a una serie de privilegios excluyentes por sobre otros modos de vida y constituciones identitarias que siguen quedando fuera de los cuerpos de la nación. En esa misma línea la activista trans Niki Raveau (ROBLES, 2019), de Fundación Transitar, advierte:

\footnotetext{
El matrimonio igualitario, como conquista oficialista LGBTI ahoga, oculta todas esas otras luchas verdaderamente urgentes. Cuando las escuelas no son centros de innovación y pensamiento se transforman en modelos de mercado heterosexual, donde sólo pasan coladas las colas bien disimuladas y con recursos. Nuestro trabajo debe revisarse,
}

\footnotetext{
9 En palabras de Puar (2013, p. 336): "el homonacionalismo es una categoría analítica desplegada para entender e historizar cómo y por qué el status de una nación como 'gay-friendly' se ha convertido en deseable", articulando -y reiterando con ella - exclusiones de raza, género, sexo y clase "no deseables".
} 
los discursos y agendas LGBTI inamovibles e incuestionables deben ser cuestionados [...] Los cambios legales e institucionales son mínimos (por ejemplo, la incompleta Ley Antidiscriminación), cuando no son las propias instituciones las que fomentan la transfobia y la inexistencia de comunidades (borrado de personas).

Si la conciliación no puede ser pactada con los colectivos LGBTI+ a costa de la supresión de su propia radicalidad, sucede lo mismo con algunos intentos de alianzas actuales con colectivos feministas que están en primera línea de batalla contra el Estado de Piñera. A días del 8M de 2020 el mandatario pasa de modo eufemístico de poner a disposición el Ministerio de la Mujer y la intendencia de Felipe Guevara para coordinar en conjunto y proveer seguridad al evento, a sostener en los medios de comunicación que "no es solo la voluntad de los hombres de abusar, sino también la de las mujeres de ser abusadas". Frente a esos intentos, la Coordinadora Feminista respondió con el siguiente comunicado el 26 de febrero (PLAN..., 2020):

En Santiago hemos decidido no pedir autorización para marchar ya que no vamos a dialogar con un intendente que es un agresor de mujeres ${ }^{10}$ y que ha sido responsable de una de las estrategias más brutales de la represión estatal: el copamiento policial. [...] Ocuparemos todas las estrategias, ya sean jurídicas o políticas, para cuidarnos entre nosotras y para garantizar nuestro derecho a la protesta.

Dos cosas quedan completamente en claro luego de leer el comunicado, en primer lugar que el Estado es el responsable de la violencia y la persecución, incluso el enemigo, y que la seguridad no puede ser de ningún modo externa al movimiento -como bien pintaron las mexicanas": "no nos cuida la policía sino nuestras amigas". En segundo lugar, que no hay posibilidad de ningún tipo de negociación con el gobierno, que cualquier acuerdo con Piñera sería parte de una suerte de claudicación. Ambos puntos - la reconciliación conciliarista y la desconfianza negacionista -, encienden las alarmas ante los pactos que todavía reverberan en la memoria de la ceniza de la salida dictatorial y la transición democrática chilena.

10 Felipe Guevara, intendente de Santiago De Chile (actualmente suspendido de su cargo por la cámara de diputados, tras acusaciones por mal desempeño de sus funciones en medio de la revuelta), fue denunciado en 2006 por violencia intrafamiliar por su esposa.

11 Entre el 9 y el 12 de agosto de 2019 fueron denunciadas dos violaciones (una de ellas múltiple) a dos jóvenes mexicanas por parte de diferentes agentes de la policía nacional. Ante la liberación de los mismos, se realizaron innumerables manifestaciones en todo el país bajo la consigna "No me Cuidan, Me violan". Las denuncias sistemáticas contra los abusos sexuales y de autoridad por parte de las fuerzas policiales hacia las mujeres y cuerpos feminizados son desde hace tiempo caratuladas por los movimientos feministas mexicanos como crímenes de Estado. 


\title{
Reactivaciones y signos de la memoria estético-política: las viejas-nuevas yeguas del NO+
}

\begin{abstract}
Nos desplegamos en la esencias del deseo y el desacato, porque la revuelta huele a barricada y a paca quemada utilizada para difuminar sin éxito el olor de nuestros muertos [...] queremos desparramar la indecencia y la protesta. Nos organizamos y sostenemos gracias a memorias colectivizadas. (COMUNICADO..., 2019).
\end{abstract}

Como señalamos, la desobediencia - primero al pago del aumento del boleto y luego al estado de sitio - hizo de las alianzas colectivas un trazado de disputa y solidaridad contra el Estado a partir del estar juntxs en la calle "hasta que valga la pena vivir" como clamaban Ixs chilenxs. El derecho a aparecer hizo de la Marcha de la dignidad, del 25 de octubre, la marcha más grande en la historia desde la vuelta a la democracia chilena que movilizó a 1.2 millones de personas.

Es en ese contexto que la Coordinadora Feminista recupera la genealogía de las memorias de las resistencias estético-políticas realizadas en dictadura y las reactualiza. El NO+ fue una consigna breve, de código abierto, anónima y sin firma particular, escurridiza de los sistemas de representación (políticos y estéticos) de las vanguardias de izquierda latinoamericanas de los 80 . Fue un signo clave en las protestas de intervención del grupo CADA (Colectivo de Acciones de Arte) ${ }^{12}$ durante los años 1983-1989 en plena dictadura pinochetista y volvió a ganar la calle de modo virulento en las jornadas de protesta de octubre de 2019.

$\mathrm{Si}$ el $\mathrm{NO}+$ era un rastro de una comunidad invisible que va dejando la huella de un afecto -como señalaron Carvajal, Longoni y Vindel (2014) y Longoni (1999) -, regresa ahora como un grito de guerra y resistencia, y cobra espesor en conflictos específicos del presente. Si para el CADA la clave estaba en $\mathrm{NO}+$ muertos ni desaparecidos y $\mathrm{NO}+$ miedo, para la Coordinadora y la voz anónima que vuelve a la calle, lo que no va más es el laboratorio neoliberal chileno pero tampoco sus abusos represivos y policiales en clave sexo-genérica: "No + abusos, No + represión, No + muertes,

\footnotetext{
12 El grupo estuvo conformado por Lotty Rosenfeld, Juan Castillo, Fernando Balcells, Raúl Zurita y Diamela Eltit. Comenzaron a realizar la acción en 1983 en el contexto de protestas sociales y reacción a las crisis económicas que la inflación y las cesantías laborales ya prefiguraban del modelo neoliberal chileno. Como señala Gonzalo Muñoz (1989, p. 233) el CADA no operó en una ciudad disponible sino que trabajó "sobre la ciudad sitiada, la ciudad del fracaso del proyecto brigadista, donde ese proyecto ha sido arrasado, borrado. Y no recurre ya a la producción de imágenes, ni símbolos, sino que genera dispositivos que, como el $\mathrm{NO}+$, funcionan como un articulador de espacios y gestos simbólicos".
} 
$\mathrm{No}+\mathrm{AFP}{ }^{13}, \mathrm{No}_{0}+$ educación de mercado, $\mathrm{No}_{0}+\mathrm{TPP}_{11}{ }^{14}, \mathrm{No}_{\mathrm{o}}+$ miedo, $\mathrm{No}+$ sexismo en la educación, No + impunidad, No + deudas, No + femicidios". El $\mathrm{NO}+$ como un dispositivo que reinscribe insistentemente su negación y produce un imperativo del NO, como un llamado a un deseo político (Figura 1).

Como señala Javiera Manzi, la vocera de la Coordinadora, al negarse a pedir autorización para la marcha del $8 \mathrm{M}$, el no permitir que "sean ellos los que propongan los términos de la paz" se transforma no sólo en una negativa a cumplir órdenes sino, además, en una transformación de los términos en que se negocia. Decir NO como estrategia de visibilización de la violencia que se enfrenta (CARRILLO VIDAL; MANZI ARANEDA, 2020). EI NO+ toma la relevancia de aquello que se está dispuesto a hacer como intervención para resistir ante los embates del Estado pero, por sobre todo, como diría Ahmed (2018), señala un modo específico de frenarse a uno mismo y (colectivamente) de transformarse en algo. "No" es decir no a esa forma extractivista y exitista de construcciones subjetivas neoliberales, dejar de estar sometidxs a los modos conocidos de construcción del poder hegemónico.

Figura 1: $\mathrm{NO}+$

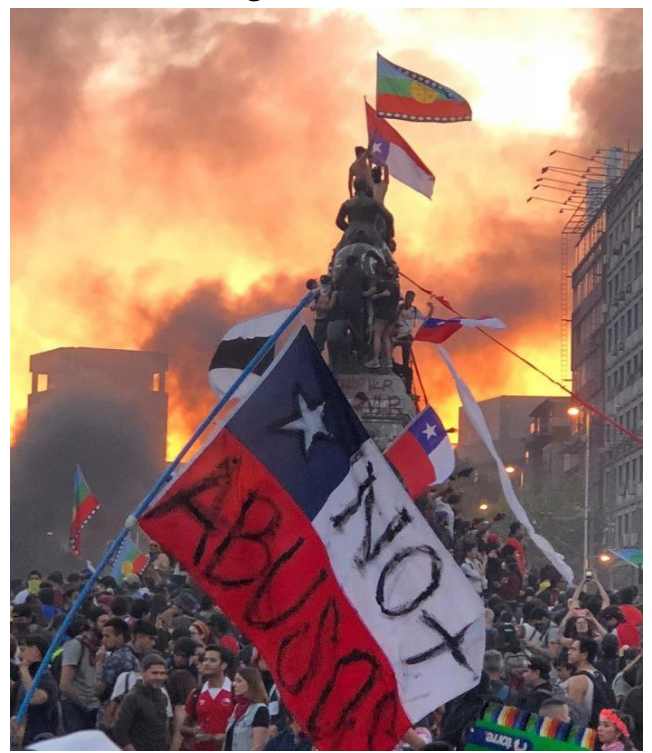

Fuente: Instagram de Susana Hidalgo (2019) ${ }^{15}$.

13 Las Administradoras de Fondos de Pensiones son las agencias privadas de ahorros de pensiones.

14 Se conoce como el TPP11 al acuerdo de libre comercio Trans-Pacific Partnership (Acuerdo Transpacifico de Cooperación Económica), firmado por los gobiernos de Australia, Brunei, Canadá, Chile, Japón, Malasia, México, Nueva Zelanda, Perú, Singapur y Vietnam.

15 Disponible en: https://bit.ly/307DHNP. Acceso en: 13 jul. 2020. 
Mientras el $\mathrm{NO}+$ grita desde el anonimato, unos cuerpos feminizados caminan por las calles con grandes colas de caballo colgadas del culo y son captadas por diferentes noticieros locales y vitoreadas por manifestantes anónimxs. Se trata de la Yeguada Latinoamericana, un colectivo artístico y performático que si bien estaba formado desde febrero de 2018 cobró visibilidad al calor de las revueltas de 2019 y, en particular, en la gran marcha del 25 de octubre. El "núcleo duro" del grupo está compuesto por las actrices y performers Cheril Linett, Fernanda Lizana, Isidora Sanchez, Cindy Maturana y Mariella Silva, aunque van oscilando en la cantidad de las integrantes necesarias para cada acción y han llegado a conformar grupos de más de treinta cuerpos en las calles. Las yeguas se declaran en guerra y en resistencia, utilizan sus cuerpos para frenar el paso de los hidrantes de la policía, para imitar un desfile militar y patriótico, o bien, para esparcirse como "yeguas locas" en goce colectivo en las calles de Santiago en resistencia.

En noviembre, lanzaron una de sus video-acciones que convocaba a "la puebla" latinoamericana frente a la precarización de la vida en el laboratorio neoliberal y las sistemáticas violaciones a los derechos humanos provocadas por Sebastián Piñera. A lo largo de una performance declarativa de casi cinco minutos el manifiesto sentenciaba: "Chile está acabando, lo estamos haciendo acabar [...] Hoy la vida, tal como la conocimos, no va más", y continuaba señalando a sus enemigos como los caudillos políticos empresariales, las multinacionales y los monumentos ${ }^{16}$. No es menor observar el descalce sobre la ocupación del espacio público como la marca del trazado colonial y sexo-genérico que por años moldeó y modeló la ciudad: "Salimos a las calles con o sin permiso legal para reunirnos en el calor y las cenizas [...] nos volvemos a ver a las caras [...] lo queremos todo, aún nada ha cambiado. No volveremos a lo mismo" (COMUNICADO..., 2019).

Hablar de la yeguada es, sin dudas, volver a trazar otra de las genealogías de resistencia estético políticas de Chile como las Yeguas del Apocalipsis, el grupo que en 1988 conformaron Francisco Casas y Pedro Lemebel en plena retirada y declive de la dictadura pinochetista. Yeguas que generaron cruces entre cuerpo, vida y violencia política que indefectiblemente hacen eco en la Yeguada Latinoamericana. La reapropiación del insulto de y sobre los cuerpos

\footnotetext{
16 En tres meses de revuelta popular al menos setenta monumentos quedaron intervenidos, derrocados o destruidos. Se tratan mayoritariamente de estatuas de conquistadores y militares. Ha habido también algunas reasignaciones interesantes que hablan de los nuevos reconocimientos y las críticas a la historia oficial colonial y sexista: en La Serena la estatua del colono español fue destruida y cambiada por la de una mujer diaguita; en Temuco (ciudad con mucha población mapuche) la estatua del fundador de Santiago, Pedro de Valdivia, fue derrocada y la cabeza del colono apareció colgada en la mano del guerrero Caupolicán, quien representa la resistencia ante el Imperio Español.
} 
desclasados y feminizados, las yeguas ${ }^{17}$, de nuevo - pero nunca iguales -, reclaman el derecho a aparecer, con sus colas de caballo colgando y caminando sobre las calles de Santiago contra la disciplinariedad de los cuerpos y la Patria Chilena como fundamento. El insulto, en ambos grupos, traza una genealogía de la recuperación de la injuria; el apelativo "yegua", y su colectivización en "yeguada", atraviesa un sinfin de reapropiaciones sin tener que dar cuenta de su transversalidad histórica (tal es asi que, extrañamente, las Yeguas del Apocalipsis no son invocadas explícitamente en la Yeguada Latinoamericana). Las yeguas de Casas y Lemebel encarnaban las colizas asoladas por la pandemia del $\mathrm{VIH}$-sida y desplazadas de la izquierda partidaria tradicional. Atisbos de un grito solitario de reconfiguración entre una vida posible y un activismo disidente sexual que todavía estaba por inventarse en un Santiago de Chile asolado por el conservadurismo moral y religioso impuesto a base de muerte y desaparición y cuya apertura cultural y política no recepcionará aséptica el apocalipsis yeguo. Descalzadas de sus sentidos fijos, las yeguas pueden ser un grupo de dos maricas en la postdictadura o un colectivo de mujeres en los estallidos chilenos de bien entrado el siglo XXI.

La yeguada no sólo invierte la injuria sobre el cuerpo animalizado y feminizado sino también se reivindica como la identidad mestiza (y mutante, dirán ellas) de la memoria chilena. Así pueden decir que son "las perras, las zorras, las cerdas, las vacas, $y$ todas aquellas sometidas por el antropocentrismo patriarcal, colonizador y neoliberal, que explota e invisibiliza todo cuerpo no hegemónico, lo controla y somete en nombre de la "humanidad" y el progreso". Las monturas, la desacralización de la militarización y la conquista, vuelven a aparecer como marca de las yeguas. Si Casas y Lemebel se burlaban de la entrada de Valdivia, las yeguas del 2019 disputan la mirada de lxs pacos contra las violencias sexistas, las violaciones y los abusos sexuales hacia mujeres, lesbianas, trans y travestis. La yeguada enuncia así que "no quiere poner como símbolo de lucha ni nuestras tetas, ni nuestra vulva, sino que nuestro culo, nuestro ano, nuestra cola"18. Ahora bien, sobre este último punto, debemos indicar en las

\footnotetext{
17 Como señala Carvajal (2012, p.`266): "en Chile, el nombre yegua corresponde a una figura de sometimiento sexual, la yegua sería la montada en el sentido sexual y militar del término. De modo que yegua designa de forma despectiva, tanto a la mujer exuberante o provocativa como al homosexual". Ambos sentidos se juegan en los dos grupos. La yeguada se reivindica más en la mujer exuberante y sexual, las yeguas, trazaron su accionar como maricas visibles.

18 Imposible no señalar las resonancias con el Manifiesto de Pedro Lemebel Hablo por mi diferencia (1986) donde señalaba las complicidades homofóbicas aun de la izquierda chilena "Mi hombría es aceptarme diferente/ Ser cobarde es mucho más duro/Yo no pongo la otra mejilla/Pongo el culo compañero/Y ésa es mi venganza/Mi hombría espera paciente/Que los machos se hagan viejos/Porque a esta altura del partido/La izquierda tranza su culo lacio/En el parlamento."
} 
recepciones de la yeguada la crítica intestina, aun desde algunos sectores feministas, hacia la sobresexualización de los cuerpos femeninos, una incomodidad sobre cómo puede conjurarse el desmarque del antropocentrismo y las violencias sexistas y patriarcales reivindicando una yegua sexual y sexualizada.

Si en el apocalipsis de las yeguas se cruzaban el erotismo marica, los reclamos por Derechos Humanos contra la violencia política estatal y una reinversión de los signos patrios y nacionalistas (por ejemplo en la famosa Cueca chueca), en la perfomance Estado de Rebeldía, realizada el 25 de octubre de 2019, la Yeguada Latinoamericana teje alianzas de cuerpos en las calles que, contra el orden de la quietud, desobedecen erotizadamente (Figura 2). Si el Estado de rebeldía es una respuesta al estado de sitio y emergencia impuesto, las yeguas, las de ahora y las de la memoria ardiente del apocalipsis de los 80, vuelven a desafiar los sentidos fragmentarios del autoritarismo patriarcal y estatal, la violencia sexista y homofóbica, así como los modos de imaginar la resistencia colectiva y reivindicar la historia viva.

Figura 2: Estado de Resistencia: Yeguada Latinoamericana

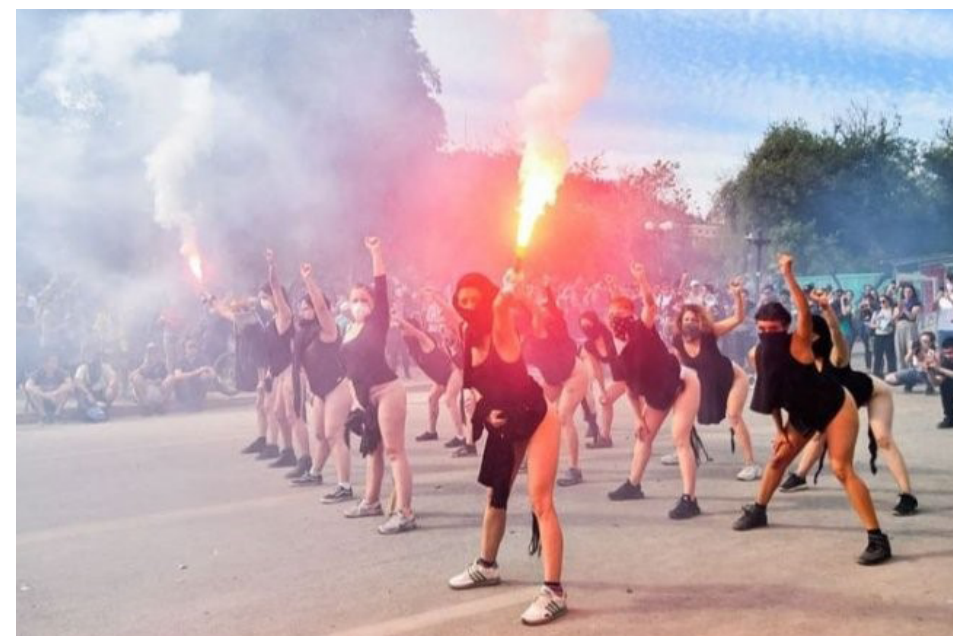

Fuente: Torres (2019).

Nuevamente, ecos que podemos recoger de las cenizas de la no conciliación democrática ni reivindicativa de las políticas de la identidad o del decoro de las Yeguas del Apocalipsis. Ambos grupos producen - de formas sustancialmente diferentes - fisuras sobre las agendas de la moralidad sexual y genérica, pero también de la flexibilización neoliberal y las violencias que estallan sobre los cuerpos de las mujeres, las maricas y lxs 
desobedientes sexuales. Si poner el culo hacía estallar los silencios y las complicidades de la izquierda, mover el culo sobre los pavimentos del siglo XXI arde a través de la revuelta. La Yeguada señala, como ese Lemebel furioso de los 80 , que sabrán ponerle el culo a las balas porque es sobre los cuerpos de mujeres, maricas, trans, lesbianas y travestis donde está la primera línea de exposición a la violencia estatal policíaca y sexual. Desde alli insisten en una renovación de los soportes de la protesta y acción callejera de poner el cuerpo, que no se reconocen ya en la Unión Popular si sus imaginarios son hetero cis patriarcales.

La intervención en y desde la calle es un modo de politizar no sólo la acción artística sino las propias ordenaciones espaciales, los valores jerárquicos que construyen el deambular de los cuerpos, de las identidades sexuales y los debates que se hacen visibles en ese espacio público. Pero también es una manera de disputar qué es y dónde se emplaza lo público para no darlo por supuesto como algo establecido de antemano. En palabras de Butler (2012, p. 99), "no es que los cuerpos sean tan sólo fuerzas vivientes mudas que se contraponen con las modalidades existentes de poder; más bien, son una modalidad de poder, de interpretaciones encarnadas, comprometidas con la acción conjunta". En este sentido también se ha inscripto el colectivo interdisciplinario de mujeres, Lastesis, formado por Dafne Valdés, Paula Cometa, Sibila Sotomayor y Lea Cáceres, que ha apostado a intervenciones potentes, sencillas, de sentencias rápidamente masificables, basadas en lecturas feministas. Su primera performance Patriarcado y capital es alianza criminal, desarrollada en 2018, se armó a partir de tesis creadas al calor de su interpretación de Calibán y la bruja de Silvia Federici (2011). Su segunda intervención pública, Un violador en tu camino, realizada el 18 de noviembre del 2019 frente a una comisaría de Carabineros en Valparaíso, era parte de una performance más amplia - que incluía parafraseos irónicos del himno de los Carabineros que vela por el sueño de las niñas inocentes y amantes - basada en lecturas de Las estructuras elementales de la violencia de Rita Segato. Reproducida, adaptada y reescrita en más de veinte idiomas, incluida la lengua de señas, contiene en la circulación de su denuncia sobre los niveles de violación del sistema patriarcal, un potente internacionalismo que también nos evoca en sus representaciones transfronterizas e intergeneracionales las añoranzas de una lucha que no se asfixie en las fronteras de la nación.

Por último, nos interesa señalar la resignificación colectiva de los usos de las capuchas que, en particular desde los movimientos feministas, son uno de los signos de las revueltas de octubre como señala 
Rocío Montes (2020). La capucha, asociada históricamente a las luchas armadas de las izquierdas latinoamericanas y vilipendiadas en los contextos neoliberales de manifestaciones contemporáneas, vuelven a emerger como íconos de la protesta pero también como parte de la autodefensa cargada de significados: taparse para protegerse y, a la par, ser vistas. El primer uso es, claramente, el del autocuidado para evitar mostrar la identidad a partir de la cual las fuerzas policiales han organizado sus redadas sobre los domicilios particulares - fundamentalmente de lxs estudiantes. El segundo es parte ya de una organización colectiva que puede leerse en diversos sentidos. Tal ha sido el grado de visibilidad de las capuchas chilenas que, en un tratamiento express, el senado aprobó en noviembre de 2019 una ley anticapuchas ${ }^{19}$ que, de hecho, desató aún más el uso y la colectivización de los saberes tanto para repartirlas gratis en las manifestaciones como para hacerlas en las casas de modo reciclado y a bajo coste. La expansión puede oírse en las consignas “¡Mujeres encapuchadas contra la ley anticapuchas!", del colectivo Capuchas Rojas en Resistencia ${ }^{20}$, o "Capuchas gratis por el derecho al anonimato", del colectivo Complejo Conejo 21 (Figuras 3 y 4). No es menor el ingreso al Congreso que hiciera la diputada Pamela Jiles (del Partido Humanista) en plena discusión de la revisión constitucional, vistiendo una capucha amarilla y al grito de "la primera línea entra hoy al Hemiciclo". La primera línea ${ }^{22}$, esa que antes era acusada de "violenta y generadora de disturbios", ahora es reivindicada en su puesta en cuerpo.

\footnotetext{
19 A principios de noviembre el gobierno de Piñera aprobó un proyecto de ley para penalizar el uso de capuchas en espacios públicos. La iniciativa prohíbe el uso de cualquier elemento que oculte el rostro de lxs manifestantes y aumenta la pena de entre 500 días a 3 años de prisión para quien realice desórdenes públicos con el rostro oculto.

20 Capuchas Rojas en Resistencia se formó durante los meses de octubre en las manifestaciones cercanas a Plaza la Dignidad y llegaron a realizar acciones con más de 200 encapuchadxs en distintos puntos de la ciudad de Santiago.

21 Complejo Conejo, es un colectivo de arte textil que trabaja alrededor del concepto del derecho al anonimato y la creación de máscaras. Durante los meses de protesta se dedicó a la confección de capuchas con telas donadas, que luego entregaban de forma gratuita en las manifestaciones del centro de Santiago.

22 Se le dice primera línea, en Chile a quienes encabezan las manifestaciones. En todas estas revueltas, el lugar de las mujeres y lxs encapuchadxs ha sido fundamental, como bien señalaba la Coordinadora Feminista todavía en el 8M del 2020: "Seremos la primera línea contra el terrorismo de Estado". A modo de ejemplo, podríamos señalar una pegatina anónima que inundó las calles de Santiago luego de las primeras semanas de manifestaciones que decía: "Tengo miedo, capucha/de que el borde de la tarde, el temido grito flote,/pero cuando capucha/jugueteas con la muerte yo me olvido de mi miedo y en ti creo capucha/te aliento capucha/ marichiwen capucha". El giro simbólico de la primera línea y las capuchas hubiera sido impensable en el contexto previo a octubre de 2019.
} 
Figura 3: Derecho al anonimato

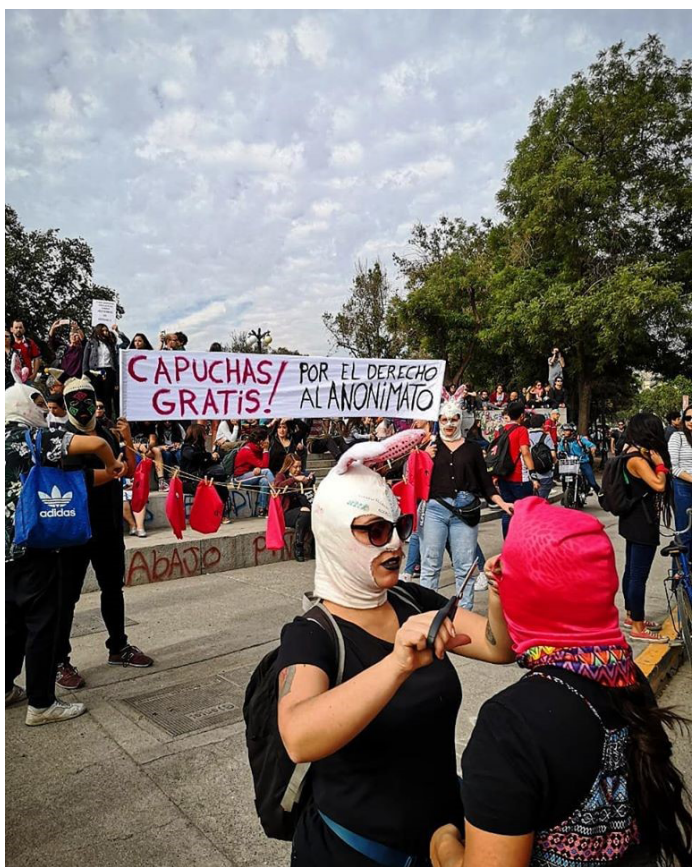

Fuente: Instagram de Complejo Conejo (2019) ${ }^{23}$.

Si el esténcil o la pegatina de bajo costo anónima caracteriza el $\mathrm{NO}+$, las capuchas conforman otro tiempo y otro saber colectivo dispensado específicamente desde los feminismos y organizados en largas horas colectivas y públicas de costura en las manifestaciones. Si bien, como señalamos, recupera la tradición de izquierda del uso de la capucha negra, se le superponen otros sentidos tanto de la cultura popular latinoamericana (las capuchas mexicanas de la lucha libre) como la reivindicación de los saberes de la costura y el bordado como aquel histórico reducto de las mujeres en el complejo y amplio espectro de las "artesanías". Antes que el negro, el color rojo parecería ser el más utilizado en las manifestaciones chilenas. Algunas señalan su uso por su histórico sentido sobre el color de las izquierdas, otras sobre la recuperación de la sangre de las asesinadas, en un guiño feminista de visibilización de los feminicidios y las violencias sistemáticas sobre los cuerpos de las mujeres.

La capucha como un traje de guerra que oculta el rostro individual pero que señala las inscripciones propias al añadirle retazos de tela, colores, lentejuelas, símbolos mapuches, texturas, pedrería, plumas y hasta mostacillas. 
Un elemento de protesta que cobra valor como proceso colectivo de creación y autocuidado, como marca frágil de protección ante gases y balines - "sus ojos son tus ojos, tus ojos son mis ojos", dirán las Capuchas Rojas en Resistencia, ante lxs incontables heridxs oculares en las revueltas.

Figura 4: Capuchas rojas en resistencia

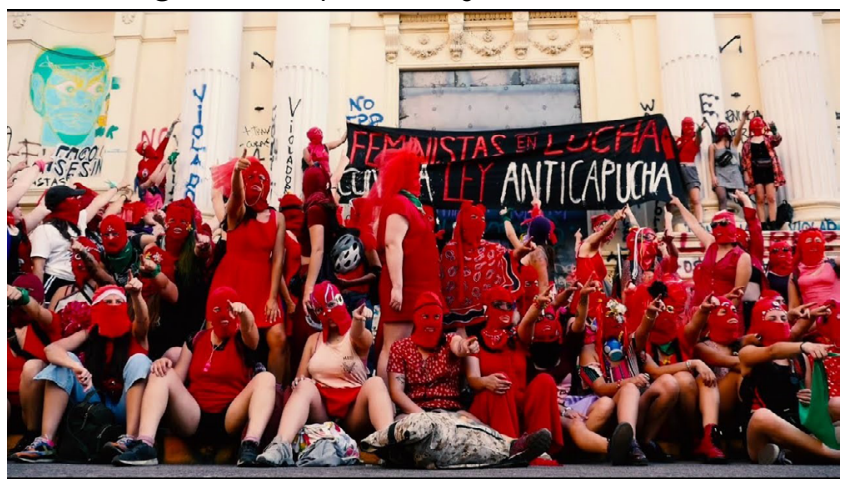

Fuente: UN VIOLADOR... (2019).

En síntesis, podríamos decir que todos estos colectivos son tan sólo un ejemplo de las innumerables acciones de resistencia estético-política feministas que se produjeron durante las manifestaciones y revueltas en Santiago. Acciones que volvieron sobre las cenizas de la historia que, como bien señalaban en el $V$ Comunicado intergaláctico, ganaron la calle para "despejar la confusión que nos hizo imaginar nuestra derrota, inclinando nuestras impotencias y angustias en ofensiva. Componer juntas, juntos, juntes la rítmica de la autodefensa donde todos somos un cuerpo informe, anomalías ruidosas frente al estandarizado silencio de la derrota".

\section{Conclusiones}

No volveremos a la normalidad, porque la normalidad era el problema. Proyección clandestina sobre edificio en Santiago de Chile, octubre 2019. [...]

Es un ambiente alienigena, el de la calle. Los manifestantes descubren que pueden encandilar a los pacos con rayos verdes de pequeños láseres comprados en la esquina. Estos rayos atraviesan la noche extraterrestre de la protesta para impedir los disparos a los ojos.

Lina Meruane, Ojos Abiertos 
El oasis neoliberal del cono sur no deja de estallar junto con la promesa presidencial de recomposición, mientras el país donde parecía que la dictadura no se había ido nunca muestra los fermentos de un desencanto que no da tregua. En uno de los países latinoamericanos donde la combinación aterradora entre el ideal capitalista de progreso meritocrático y el desarrollo cada vez más atroz de prácticas y discursos de odio propios del neoliberalismo hiper-reaccionario parecía en una escalada sin fin, una resistencia liderada por jóvenes - atravesadxs por históricas luchas feministas, cuir, antiimperialistas, ecologistas y decoloniales - ha ocupado todo. Si bien su punta de lanza es el movimiento estudiantil (ellxs prefieren decir: "jamás vanguardia, siempre autodefensa"), el estallido es fuertemente intergeneracional: madres, padres, abuelxs, allegadxs, endeuda$d x s$, precarizadxs, que en muchos casos comparten la bronca - y a veces incluso la vergüenza - de no haber podido hacer todo esto antes, de haber aguantado tanto. Lo "inesperado" del estallido, sin embargo, también se recuesta en el desconocimiento fomentado por parte de los medios de comunicación de procesos de resistencia sostenidos en el tiempo. Lo inesperado surge de no vincular - y por ende vaciar de densidad histórica - momentos de rebelión muy importantes de la historia reciente chilena: la "marcha de los pingüinos" del 2006; la rebelión de lxs estudiantes universitarixs en el 2011; el movimiento contra las AFP; los levantamientos sociales en Freirina, Aysén, Chiloé; y los procesos de denuncia, escrache, movilización y toma de facultades que tuvieron lugar entre el 2017 y el 2018 por parte del feminismo.

En este marco, como hemos intentado mostrar a lo largo del artículo, los feminismos chilenos y la larga tradición de resistencia cuir, anticolonial y sudaca, han sido y son, en muchos casos, el coagulante para que la movilización siga pudiendo conectar con la ira y con otros imaginarios posibles para inventar lenguajes, solidaridades e imágenes de vidas deseables. Las violencias y las resistencias políticas han sido reconfiguradas en postales y reapropiaciones que oscilan entre la animalidad (la injuria vuelta potencia y archivo ${ }^{24}$ ) y lo alienígena. Sobre esto último las metáforas de la "invasión" utilizadas por la primera dama para caracterizar la rebelión, junto con las instantáneas iluminadas por el fuego de los incendios y las balas, resistidas por un ejército improvisado con capuchas de lentejuelas y láseres verdes que desafian los carros hidrantes que largan soda cáustica, dan letra - en su dislocamiento de los tiempos, los espacios y los cuerpos - a que un internacionalismo feminista e izquierdista expanda sus

24 El lugar otorgado a las alianzas con la animalidad ha sido extenso y de una recepción popular masiva durante las revueltas. Sólo por citar un ejemplo la iconografía y simbología creada en torno al perro matapaco en distintas ciudades chilenas. Disponivel em: https://bit.ly/2VBpNCu. Acesso em: $1^{0}$ jul. 2020. 
horizontes de decibilidad permanentemente. La otredad de sí, el proceso de extrañamiento constante que tanto aterra al establishment chileno en plena pérdida de libreto, se reconfigura insidiosamente todo el tiempo en feminismos cuya urgencia programática no pareciera inhibir un zigzagueo imaginario sobre las posibilidades de la contingencia y su nueva inscripción en ella. Un potente uso irónico sobre sí y un conjunto de avisos que nunca pierden el tono de amenaza, dan la impresión de un proceso abierto de subjetivaciones políticas que no se dejan cooptar por la lógica de las agendas.

Así, por ejemplo, en medio de la crisis actual por el coronavirus la Coordinadora Feminista chilena llama a llevar la huelga en todas aquellas actividades productivas que no estén destinadas a sostener el sistema de salud, de cuidados o de abastecimiento y a cacerolear desde nuestros hogares, a promover redes de cuidado y solidaridad para que el aislamiento necesario no suponga el afianzamiento del individualismo, el abandono de personas o la no-escapatoria de la violencia perpetuada en la domesticidad. La Coordinadora propone utilizar la crisis para elaborar una crítica al vaciamiento del sistema de salud pública y azuzar un programa político anticapitalista donde se anteponga el cuidado de las personas al cuidado de las ganancias. Se lee en el comunicado: "Enfrentamos una crisis que intensifica la precarización, las violencias patriarcales y racistas, además de la crisis global ecológica y de cuidados, en este contexto, levantamos este plan como un llamado a cuidarnos y a impulsar acciones que exijan y levanten alternativas desde los pueblos en clave anticapitalista y feminista frente la coyuntura" (2020). En la misma tesitura, el acampe de la Plaza de la Dignidad, que tuvo que levantarse por motivos sanitarios, amenaza contundente al gobierno: "Tarde o temprano vamos a volver y recordaremos en este tiempo de pandemias cuáles fueron sus prioridades". Es interesante reparar no sólo en la reconfiguración del estado de alerta que hace que las denuncias no queden cooptadas por la agenda de seguridad sino en cómo, pese a la insistencia de la metáfora viral para caracterizar la violencia sexista, hay una lucidez política que se repone a esa tentación y la politiza. En ese movimiento también reaparece la polémica noción de "guerra", que analizamos al inicio, como estrategia útil. Como señala Verónica Gago (2019, p. 69), "la noción de guerra permite subrayar una dinámica de fuerzas en disputa y despejar nociones como la de epidemia o brote". Por otra parte, pelearse con la metáfora viral también posibilita ajustar responsabilidades sociales, pensar nuevos diagnósticos y evitar el chicaneo de la "ineficacia preventiva" (GAGO, 2019), por el que las marchas masivas del 
feminismo sólo acrecentarían la reacción y, por ende, las muertes por femicidios y travesticidos.

La conciencia de estos corrimientos es la forma más palpable de registrar los nuevos procesos de subjetivación feminista explorados en el reciente estallido. La guerra de posiciones no se detiene ante la imposibilidad de la ocupación de las calles y los espacios públicos, la politicidad de lo personal, lo doméstico y lo cotidiano no dan tregua en su articulación con agendas anticoloniales, anticapitalistas y antipatriarcales, "hasta que valga la pena vivir".

\section{Referencias}

AHMED, S. No. Traducción Nicolás Cuello. In: CUELLO, N.; DISALVO, L. (comp.). Críticas sexuales a la razón punitiva: insumos para seguir imaginando una vida junt*s. Buenos Aires: Ediciones Precarias, 2018. p. 153-164.

BUTLER, J. Marcos de guerra: las vidas lloradas. Buenos Aires: Paidós, 2010.

BUTLER, J. La alianza de los cuerpos y la política de la calle. Debate Feminista, Ciudad de México, v. 23, n. 46, p. 91-113, 2012.

BUTLER, J. Entrevista a Butler: es tiempo de que el Norte siga al Sur. Plaza Pública, Washington, 17 ene. 2020. Disponible en: https://bit.ly/3ghZOCV. Acceso en: 3 mar. 2020.

CARRILLOVIDAL, A.; MANZI ARANEDA, J. Nuestras luces en la penumbra: potencia feminista y urgencias destituyentes. In: GAGO, V.; MALO, M.; CAVALLERO, L. (comp.). La Internacional Feminista: luchas en los territorios y contra el neoliberalismo. Buenos Aires: Tinta Limón, 2020. p. 93-108.

CARVAJAL, F. Las yeguas del Apocalipsis: cruces entre arte, sexualidad y política en el pasaje entre dictadura y posdictadura en Chile. In: AZNAR, Y.; MARTÍNEZ, P. (ed.). Lecturas para un espectador inquieto. Madrid: CA2M, 2012. p. 264-275.

CARVAJAL, F.; LONGONI, A.; VINDEL, J. Socialización del arte. In: MUSEO REINA SOFÍA. (comp.). Perder la forma humana: una imagen sísmica de los años ochenta en América Latina. Madrid: Museo Nacional Centro de Arte Reina Sofía, 2014. p. 226-235. 
COMUNICADO. Direção de Cheril Linett. Santiago: Yeguada Latinoamericana, 2019. 1 video (9 $\mathrm{min}$ ), color. Disponible en: https://bit. ly/3esFhPF. Acceso en: 14 jul. 2020.

COORDINADORA FEMINISTA 8M. Columna: Este 8 de marzo, ¡La Huelga Feminista VA! The Clinic, Santiago,8 enero 2019. Disponible en: https://bit.ly/3gVOyRU. Acceso en: 14 jul. 2020.

COORDINADORA FEMINISTA 8M. Lo inadmisible es la represión estatal \#LaHuelgaFeministaVa. Santiago, 26 fev. 2020. Disponible en: https://bit.ly/3glyXed. Acceso en: 17 mar. 2020.

DYSTÓPICA, V. (ed.). No tengo fuerzas para rendirme: saberes desde la revuelta en shile. Buenos Aires: Chauín, 2019.

FEDERICI, S. Calibán y la bruja. Buenos Aires: Tinta Limón, 2011.

GAGO, V. La potencia feminista: o el deseo de cambiarlo todo. Buenos Aires: Tinta Limón, 2019.

INSTITUTO NACIONAL DE DERECHOS HUMANOS. Informe anual 2019: situación de los derechos humanos en Chile en el contexto de la crisis social. Santiago: INDH, 2019.

LEMEBEL, P. Manifiesto (hablo por mi diferencia). Anales, Santiago, v. 7, n. 2, p. 218-221, 1986. Disponible en: https://bit.ly/38flBMC. Acceso en: 16 mar. 2020.

LONGONI, A. Brigadas muralistas: la persistencia de una práctica de comunicación político visual. Revista de Crítica Cultural, Santiago, n. 19, p. 22-25, 1999.

MEDEAK. Violencia y transfeminismo. Una mirada situada. In: SOLÁ, M.; URKO, E. (comp.). Transfeminismos: epistemes, fricciones y flujos. Tafalla: Txalaparta, 2014. p. 73-80.

MERUANE, L. Ojos abiertos. Plaza pública, Santiago, 17 dic. 2019. Disponible en: https://bit.ly/2NMWkAY. Acceso en: 20 mar. 2020. 
MONTES, R. Cubrirse el rostro para ser legión: el icono de la lucha feminista en Chile. El País, Santiago, 7 mar. 2020. Disponivel em https://bit.ly/2ZqnenD. Acceso en: 17 mar. 2020.

MUÑOZ, G. El gesto del otro. In: BIERBAUM, T.; GÜNTER, B.; MATTHIAS, R. (ed.). Cirugía plástica. Berlín: NGBK, 1989. p. 233.

PLAN de emergencia feminista ante la crisis del coronavirus. Coordinadora Feminista 8M, Santiago, 27 mar. 2020. Disponible en: http://cf8m.cl/. Acceso en: 20 mar. 2020.

PRECIADO, P. Repensando el concepto de violencia sexista... Feminismos para el siglo XXI. Donostia: [s. n.], 2009.

PUAR, J. Terrorist assemblages: homonationalism in queer times. Durham: Duke University Press, 2007.

PUAR, J. Rethinking homonationalism. International Journal of Middle East Studies, Cambridge, v. 45, n. 2, p. 336-339, 2013.

ROBLES, V. H. Cuando las travestis chilenas tomaron las calles. Agencia Presentes, Buenos Aires, 22 abr. 2019. Disponible en: https://bit.ly/2NNYGje. Acceso en: 17 mar. 2020.

SEGATO, L. R. La guerra contra las mujeres. Buenos Aires: Tinta Limón, 2017.

TORRES, C. Chile: Yeguada Latinoamericana en "Estado de Rebeldía". La Izquierda Diario, Santiago, 13 nov. 2019. Disponible en: https://bit.ly/30lj4hB. Acceso en: 13 jul. 2020.

UN VIOLADOR en tu camino: capuchas rojas en resistencia. Santiago: [s. n.]. 1 vídeo (2 min.). Publicado pelo canal Cons Gallardo. Disponible en: https:// bit.ly/2ZoQRXz. Acceso en: 13 jul. 2020.

WOLIN, S. Política y perspectiva. Buenos Aires: Amorrortu, 2001.

Recebido em março de 2020.

Aprovado em junho de 2020. 